\title{
Effectiveness of a confinement strategy for reducing campsite impacts in Shenandoah National Park
}

\author{
SCOTT E. REID ${ }^{1}$ AND JEFFREY L. MARION ${ }^{2 *}$ \\ ${ }^{I}$ Department of Forestry, Virginia Tech University, 305 Cheatham Hall (0324), Blacksburg, VA 24061, USA and ${ }^{2}$ USGS Patuxent Wildlife \\ Research Center, Virginia Tech Cooperative Park Studies Unit, 304 Cheatham Hall (0324), Blacksburg, VA 24061, USA \\ Date submitted: 8 September 2003 Date accepted: 20 September 2004
}

\section{SUMMARY}

The expansion and proliferation of backcountry campsites is a persistent problem in many parks and protected areas. Shenandoah National Park (SNP) has one of the highest backcountry overnight use densities in the USA national parks system. SNP managers implemented a multi-option backcountry camping policy in 2000 that included camping containment with established campsites. These actions were intended to reduce the number of campsites and the area of camping disturbance at each site. This paper describes a longitudinal adaptive management assessment of the new campsite policies, applying quantitative measures of campsite conditions to evaluate the efficacy of management interventions. Physical campsite measurements combined with qualitative visitor interviews indicated SNP had successfully reduced the number of campsites and aggregate measures of camping-related disturbance in the Park, while minimizing the use of regulations, site facilities and staff resources. Implications for managers of other protected areas are that an established site camping policy can minimize camping disturbance, including the number and size of campsites, provided managers can sustain rehabilitation efforts to close and restore unneeded campsites. Experiential attributes, such as the potential for solitude, can also be manipulated through control over the selection of established campsites. Integrating resource and social science methods also provided a more holistic perspective on management policy assessments. Adaptive management research provided a timely evaluation of management success while facilitating effective modifications in response to unforeseen challenges. Conclusions regarding the effectiveness of a visitor impact containment strategy involving an established site camping option are offered.

Keymords: adaptive management, campsite impacts, camping policies, campsite impact monitoring, recreation ecology

\footnotetext{
* Correspondence: Dr Jeffrey Marion Tel: +1 5402316603 Fax:

+15402313698 e-mail: jmarion@vt.edu
}

\section{INTRODUCTION}

In parks and protected areas, backcountry recreation in the USA is typically focused on trails and campsites, which provide access to public lands, facilitate recreational opportunities and concentrate traffic to protect natural resources. Campsites are of particular concern because overnight visitors cause intensive trampling associated with cooking, sleeping and social activities. Managing campsites to limit the areal extent and severity of camping-related resource impacts is particularly challenging for the USA National Park Service (NPS) managers, who operate under the guidance of the Organic Act (16 USC 1) and the Wilderness Act (16 USC 1131-1136). These laws direct the NPS to provide for recreational access to public lands in such a manner as will leave them unimpaired for future use and enjoyment (NPS 2001).

Empirical research has consistently shown that recreational use of public lands and campsites inevitably causes resource degradation, which can affect natural ecosystem functions and compromise the quality of visitor recreational experiences (Hammitt \& Cole 1998; Leung \& Marion 2000). Common campsite impacts include vegetation loss, exposed soil, erosion, tree damage and fire scars (Cole 1989a). Research has also documented a curvilinear relationship between the amount of site use and site condition. The majority of impacts occur with initial and low levels of use, while subsequent use adds minimally to cumulative degradation (Cole 1982, 1995; Cole \& Marion 1988; Marion \& Cole 1996; Newsome et al. 2002). Based on empirical studies and theoretical modelling, the most effective approach to minimizing camping impacts in moderate- to highly-visited areas is to concentrate use on a limited number of sites (Cole 1992, 1995; Leung \& Marion 1999, 2000).

USA national park and wilderness managers perceive campsite expansion and degradation as problematic in 'many' or 'most' areas of their parks (Washburne \& Cole 1983; Marion et al. 1993). A variety of management strategies have been applied to minimize camping-related impacts, including use restrictions and closures, visitor dispersal and containment, site design and management, and visitor education (Cole et al. 1997; Leung \& Marion 1999, 2000; Marion \& Cole 1996). Leung and Marion (1999) highlight four spatial strategies for managing impacts, namely spatial segregation, containment, dispersal and configuration; a combination of strategies will often provide the most effective solution. Cole (1993) 
suggested three primary approaches to preventing campsite proliferation and deterioration, namely change site selection behaviour, develop an active site management programme and improve visitor behaviour at campsites. An effective containment strategy should combine all three elements: (1) encourage visitors to camp only on well-established sites, (2) close and rehabilitate fragile, low-use, unacceptably impacted or unnecessary sites, and (3) educate visitors to concentrate camping activities in core impacted portions of the site.

Evaluations of the effectiveness of camping policies in reducing resource degradation are uncommon, but have been undertaken in several settings. In an assessment of campsites in three western wilderness areas, Cole (1993) found that campsite dispersal policies often contributed to pervasive campsite proliferation problems. Cole and Ranz (1983) found that closing wilderness campsites to facilitate recovery failed to improve overall resource conditions because of ineffectual closure, slow recovery rates and the development of new visitor-created campsites.

Marion (1995) demonstrated the effectiveness of a campsite containment strategy along an eastern USA river attributed to the closure of unnecessary sites and designation of resistant sites with anchored fire grates. These actions contributed to a $50 \%$ reduction in the cumulative area of disturbance, despite slight increases in degradation on campsites left open to visitors. Similarly, a camping confinement strategy that included designating sites for stock users, site closure and restoration work substantially reduced resource impacts over a five-year period in wilderness campsites in Idaho (Spildie et al. 2000). In contrast, using pre- and post-policy campsite condition assessments in two Oregon wilderness areas, Hall (2001) concluded that a designated-site management policy yielded mixed success. Although the containment strategy effectively reduced campsite proliferation, closed sites recovered minimally while designated sites deteriorated significantly. Research regarding visitor containment strategies has therefore shown conflicting results, suggesting that additional studies are needed to improve the understanding of campsite concentration policies.

This longitudinal study reports results from one element of an adaptive campsite management strategy in Shenandoah National Park (SNP). Adaptive management is an approach of prepared responsiveness, whereby policy and management actions are integrated with feedback systems based on monitoring and evaluation (Holling 1978; Lessard 1998; Bellamy et al. 2001). Land managers implement policies and adjust prescriptions based on observed trends of change or knowledge gained from periodic monitoring efforts.

Based partially on earlier research and collaboration (Williams \& Marion 1995), SNP managers implemented a multi-option backcountry camping policy in 2000 that included camping containment with designated and established campsites, and a no-camping option (SNP 1998). This study evaluates the success of the established site camping option within three park management zones selected
Table 1 SNP backcountry visitation (nights $\mathrm{yr}^{-1}$ ) Park-wide and for the three study areas.

\begin{tabular}{lll}
\hline \hline Year & Park totals & Study areas \\
\hline 1999 & 43913 & 3621 \\
2000 & 42564 & 3316 \\
2001 & 42966 & 3006 \\
2002 & 39960 & 2926 \\
\hline \hline
\end{tabular}

to test the new policies. The established site camping option was selected for study, because managers felt it offered the greatest opportunity for visitor confusion and/or noncompliance. Research questions included: could criteria for selecting only the unmarked established sites be effectively communicated to visitors? Would total number of sites and area of disturbance associated with camping decline? Would the selected sites expand in size and impact severity? The uncertainties surrounding these questions emphasized the need to evaluate success and provided the impetus for this adaptive management study. Success was gauged by comparing campsite numbers with cumulative areal measures of disturbance, including campsite size, and area of vegetation loss and soil exposure.

An important need relative to interpreting study results on campsite numbers and conditions was the Park staff's effectiveness in informing visitors about the established site camping option and their selection of appropriate campsites. Visitor interviews were conducted with open-ended questions and follow-up clarifications to better assess subjects' understandings of the new camping policies. By integrating both longitudinal quantitative resource assessments and qualitative visitor interviews, this study provides a holistic assessment of the efficacy of a new campsite containment strategy implemented in the Park.

\section{Study Area}

SNP is located in central Virginia, within a one-day drive for $60 \%$ of the population of the USA, and has one of the highest backcountry overnight use densities in the USA national parks system (Table 1; NPS 2002). The Park runs north-south along the crest of the Central Appalachian Mountains. Day hiking and backpacking are the primary backcountry recreational pursuits in the park. Approximately $40 \%$ of SNP is federally designated Wilderness, including all areas investigated in this study.

\section{Camping policies}

SNP originally allowed 'at-large' camping, in which visitors were allowed to camp anywhere in backcountry areas. In 1972, increasing resource impacts and visitation prompted managers to restrict backcountry camping to 39 locations. By 1974 , resource and social conditions at many of these locations deteriorated to unacceptable levels as visitation increased substantially. In response, a dispersed camping policy was implemented, directing visitors to camp more than 25 feet 
from water and out of sight of trails and other campers. This dispersal policy had resulted in the creation of approximately 1300 campsites by 1983 . Because of declining visitation and a park campsite closure and rehabilitation programme, this had reduced to 725 campsites by 1994 (Williams \& Marion 1995), but $68 \%$ of these violated the Park's camping regulations.

In June 2000, SNP implemented a Backcountry and Wilderness Management Plan (SNP 1998) restricting campers to a limited number of designated campsites to inhibit site expansion in the most popular areas. In the majority of the Park, visitors use 'established' campsites selected by managers from a reduced number of former visitor-created campsites. This is a form of a containment strategy for minimizing impacts that offers greater visitor choice and more primitive sites. Finally, some areas were closed to camping because of high levels of day use or sensitive flora, fauna or cultural sites.

In 1999, Park staff recorded the number of groups and occupied campsites on six high (not peak) use weekends in the study areas. Campsite numbers substantially exceeded the number of groups within the study areas with average occupancy rates of $16 \%$. In an effort to increase occupancy levels above $30 \%$ and reduce the overall areal extent of camping impacts, managers considered distance to Park developments, water sources and trails, expansion potential, slope, groundcover composition, forest type and aspect, and sites that offered the greatest opportunity for solitude (Williams \& Marion 1995) to select a subset of sites for use.

\section{Site management and education}

SNP staff selected the highest use travel zone managed under the established site camping policy within each of the three Park districts to ensure a sufficient number of campsites for investigation. Table 1 shows use data. There was no site management on campsites selected for inclusion in the established campsite zones, although fire sites that appeared were dismantled (campfires are prohibited in SNP). All other campsites were closed and rehabilitated by piling logs, branches and leaves onto the sites. Park managers conducted a late-season trip through each travel zone once a year to locate illegal campsites and repeat this work. The type, extent, location and time required for all rehabilitation work were documented. 'Recovered sites' were sites where campsite boundaries had disappeared (i.e. vegetation and leaf litter were undisturbed and natural in appearance).

Park managers also initiated an education campaign to inform Park visitors about the new camping policy principally through the permit distribution process. SNP has issued backcountry camping permits by mail, self-served kiosks, or through their visitor centre since 1974, and Park staff estimate that $90-95 \%$ of visitors comply with the permit requirement. Campsite policies are printed on the back of each permit, in brochures, on trailhead bulletin boards and on SNP's website. Rangers also convey camping policies during routine visitor contacts.

\section{METHODS}

We assessed campsite conditions within the three study areas the summer before (in 1999) and two years after (in 2002) the implementation of new camping policies in January 2000. To minimize variability related to seasonal differences in visitation and vegetative growth patterns, all campsites were located and assessed near the end of the use and growing season. Site locations were documented with global positioning satellite (GPS) receivers and, when needed, data were used to relocate all campsites and rehabilitated sites from prior surveys.

Trained field staff applied campsite condition assessment procedures adapted from Marion (1991). Using buried metal markers as a permanent reference point, the variable radial transect method (Marion 1995) was applied to outline previous campsite boundaries and to alter them only when there was a compelling reason to do so. This procedure minimizes measurement errors associated with subjective determinations of campsite boundaries. Visually distinct differences in vegetation cover, height, disturbance or composition, and surface organic litter served as the basis for flagging campsite boundaries. The transect distance and compass bearing to each boundary flag were input to a computer programme for area calculations, and all adjacent satellite camping areas were also measured and included.

\section{Indicators of site condition}

Ten indicators of campsite condition were assessed in 1999 and 2002; three indicators relating specifically to the type and extent of ground cover disturbance are presented in this paper. Campsite area is considered the most important indicator of camping impacts because it reflects the overall areal extent of resource disturbance and is responsive to changes in visitation and management (Cole 1989a; Marion 1991). The area of vegetation loss is another highly responsive indicator, particularly at low to moderate use levels, that has ecological and social significance (Cole 1989b). Non-woody vegetative ground cover was estimated (in percentage categories $0-5$, 6-25, 26-50, 51-75, 76-95, 96-100) within site boundaries and in adjacent, undisturbed off-site 'control' areas with similar environmental attributes. Mid-point values for onsite cover categories were then subtracted from comparable offsite values, divided by 100 , and multiplied by the campsite area to yield area of vegetation loss. This measure provides an estimate of the area over which vegetation cover has been lost on a campsite.

Trampling removes vegetation cover to expose organic litter and soils; further trampling pulverizes and removes these materials to expose mineral soil. The extent of bare mineral soil exposure has been identified as a good indicator of campsite condition on highly used sites (Cole 1982; Marion \& Merriam 1985). On-site exposed soil, defined as areas with very little or no organic matter or vegetation cover, was estimated for each campsite in the same way as vegetation loss. Mid-point 
Table 2 Findings for aggregate campsite indicators for all areas and in each study area. For comparison purposes, 1999 data reflect site legality designations associated with the new camping policies implemented in June 2000.

\begin{tabular}{|c|c|c|c|c|c|c|c|c|c|c|}
\hline \multirow[t]{2}{*}{$\overline{\text { Indicators and year }}$} & & \multicolumn{3}{|c|}{ Legal campsites } & \multicolumn{3}{|c|}{ IIllegal campsites } & \multicolumn{3}{|c|}{ Total } \\
\hline & & $n$ & Mean & Sum & $n$ & Mean & Sum & $n$ & Mean & Sum \\
\hline \multirow[t]{2}{*}{ Campsite size $\left(\mathrm{m}^{2}\right)$} & 1999 & 41 & 28 & 1161 & 32 & 30 & 961 & 73 & 29 & 2122 \\
\hline & 2002 & 24 & 33 & 787 & 13 & 20 & 262 & 37 & 28 & 1049 \\
\hline \multirow[t]{2}{*}{ Vegetation loss $\left(\mathrm{m}^{2}\right)$} & 1999 & 40 & 8 & 299 & 32 & 7 & 225 & 72 & 7 & 524 \\
\hline & 2002 & 24 & 9 & 212 & 13 & 6 & 82 & 37 & 8 & 293 \\
\hline \multirow[t]{2}{*}{ Exposed soil $\left(\mathrm{m}^{2}\right)$} & 1999 & 40 & 2 & 92 & 30 & 3 & 92 & 70 & 3 & 184 \\
\hline & 2002 & 24 & 5 & 125 & 13 & 2 & 30 & 37 & 4 & 155 \\
\hline
\end{tabular}

values were divided by 100 and multiplied by campsite area to determine area of exposed soil.

\section{Inter-campsite visibility}

Cole et al. (1987) suggested that the number of visitor encounters at campsites could influence perceived levels of crowding, especially in designated wilderness areas. As a result, Farrell and Marion (2000) used an inter-campsite visibility indicator and the distance between campsites to assess the potential for visitor encounters at campsites. As indicators of the potential for solitude while camping, the distance and visibility between campsites were each assessed.

\section{Qualitative methods}

During fieldwork in the three study areas, all available campsite visitors were approached in their campsites and asked to participate in a fifteen-minute interview. Openended interview questions gauged visitors' understanding and articulation of the SNP established-site camping policy, including the nature and location of the educational message conveyed to them, and the rationales for their campsite selection. Cross-validated content analysis, as described by Neuendorf (2002), was performed to categorize interview findings. Used in a variety of settings from cultural studies to mass communications research, content analysis is a quantitative approach to qualitative data that involves categorizing subject statements into broad themes, then counting the number of comments under each theme (Manning \& Cullum-Swan 1994).

The unit of analysis was the number of times a concept was mentioned by interview subjects, rather than the number of individuals who articulated it. The number of 'mentions' or 'response units' indicates the degree to which interviewees focus on a particular aspect of the SNP camping policy and suggests the cognitive retention of certain concepts over others. Tallies for each topic are expressed as a percentage of the total response units under each broader theme. For example, 25 statements pertaining to campsite convenience out of a total of 50 responses to site selection criteria would yield a ' $50 \%$ of mentions' result. To ensure consistent interpretation and analysis of the qualitative data, independent reviewers performed content analyses and then compared their results for consistencies and discrepancies. Conclusions from the analysis are drawn only from those themes and comments consistently identified by both reviewers. The percentage of agreement between independent interview analyses was $93 \%$.

\section{RESULTS}

\section{Campsite assessments}

Following a thorough search of the study areas, field staff located and assessed 73 campsites in 1999. Forty-one of these sites remained open when the established campsite policy was initiated in June 2000 (Table 2). The remaining 32 campsites were deemed illegal, and efforts were made to close them and enable natural recovery to occur. In 2002, field staff relocated all 73 former campsites and searched for new sites. Only 37 campsites exhibited signs of use and identifiable disturbancerelated boundaries in 2002, a $49 \%$ reduction in site numbers from 1999 (Table 2). These included 21 of the 41 campsites left open for established site camping and 3 new visitorcreated sites that met site legality criteria (based in part on proximity to formal trails, other sites and water resources). Of the 13 remaining campsites, five had been present in 1999 and became illegal in 2000, and eight were new visitor-created illegal campsites. Seventeen additional campsites left open for established site camping in 2000 were not counted as campsites in 2002, because they had no appearance of use and lacked disturbance-related boundaries.

The area of disturbance attributed to camping activities, which is reflected by the campsite size indicator, was reduced by $51 \%$ (from $2122 \mathrm{~m}^{2}$ to $1049 \mathrm{~m}^{2}$; Table 2). Most of this reduction may be attributed to the greatly reduced number of campsites, although mean size for illegal sites fell from $30 \mathrm{~m}^{2}$ to $20 \mathrm{~m}^{2}$. Legal sites grew slightly in size, from a mean of $28 \mathrm{~m}^{2}$ to $33 \mathrm{~m}^{2}$, although aggregate (sum of site sizes) disturbance for legal sites fell by 32\% (Table 2).

Aggregate area of vegetation loss decreased by $44 \%$ during the study period (from $524 \mathrm{~m}^{2}$ to $293 \mathrm{~m}^{2}$; Table 2). Legal campsites experienced a slight increase in mean area of vegetation loss (from $8 \mathrm{~m}^{2}$ to $9 \mathrm{~m}^{2}$ ) though the aggregate measure declined by $29 \%$. On illegal sites, area of vegetation loss was $64 \%$ less in $2002\left(82 \mathrm{~m}^{2}\right)$ than it was in $1999\left(225 \mathrm{~m}^{2}\right.$; Table 2). Area of exposed soil also decreased during the study 
period, but the reduction (16\%) was not as dramatic as that for vegetation loss or campsite area. A $67 \%$ reduction in exposed soil on illegal sites was offset by an increase in exposed soil on legal sites $\left(92 \mathrm{~m}^{2}\right.$ to $\left.125 \mathrm{~m}^{2} ; 36 \%\right)$, attributable to an increase in the mean area of exposed soil $\left(2 \mathrm{~m}^{2}\right.$ to $\left.5 \mathrm{~m}^{2}\right)$. For the 21 campsites that were legal and established in both 1999 and 2002, mean campsite area increased slightly from $33 \mathrm{~m}^{2}$ to $34 \mathrm{~m}^{2}$, while the mean area of exposed soil increased from $3 \mathrm{~m}^{2}$ to $5 \mathrm{~m}^{2}$, and area of vegetation loss grew from $8 \mathrm{~m}^{2}$ to $9 \mathrm{~m}^{2}$.

The Park's overnight visitation declined by $9 \%$ for the Park as a whole and $19 \%$ in the study areas over the study period (visitor use data for the study areas was considered less accurate; Table 1). However, to understand changes in campsite use and condition affected by the new campsite policies, an average per-site visitation figure was calculated based on permit data reflecting annual visitation and average group size for the study areas. The number of backcountry visits for each basin was divided by the average overnight group size for that basin to obtain average nights camped per basin. An estimate of annual per-site visitation was calculated by dividing annual sums by campsite numbers. Estimated annual visitation in study area campsites was 19 nights in 1999 and 29 nights in 2002, a 53\% increase that we attribute to implementation of the established campsite policy.

An important influence on campsite solitude is the number of other visible campsites from each campsite. In 1999, the number of campsites visible from a given site ranged from $0-5$ with a mean of 1 . In 2002, the number of campsites ranged from $0-5$ with a mean of 0.4 . Distance to the nearest other campsite was also assessed and this measure increased from a mean of $15 \mathrm{~m}$ in 1999 to $18 \mathrm{~m}$ in 2002 .

\section{Rehabilitation efforts}

Once a year, during the study period, illegal sites within the study areas were covered with organic debris to discourage camping. However, although 32 campsites in the three study areas became illegal in June 2000, only 17 sites were rehabilitated in late 1999. SNP staff were unable to undertake rehabilitation work in Jeremys Run in 1999. Nine sites were rehabilitated in 2000 and eight sites were rehabilitated in 2001. During the study period, a total of 29 hours of staff time were dedicated to rehabilitation efforts, with an average of 52 minutes of work per site.

In addition to the Park staff's rehabilitation efforts, lack of visitor use and natural events such as tree falls from forest fire and insect infestations resulted in the closure and unassisted recovery of additional campsites that lacked evidence of disturbance. From a management perspective, this was defined as successful recovery, although we recognize that many years of closure to use will be required to achieve full ecological recovery with respect to vegetation composition and structure. In 1999, field staff identified only two rehabilitated sites showing recovery from previous years, while in 2002, 24 rehabilitated sites showed no evidence of reuse. In 2002, they located 15 illegal sites lacking evidence of rehabilitation work and reuse. As we noted previously, 17 of the campsites made available in 2000 were never used; these remained undisturbed in 2002 .

\section{Interview results}

We interviewed 33 visitors to evaluate their understanding and compliance with the new camping policies. Study participants' ages ranged from $9-50$, with group sizes ranging from 1-8 visitors. Although most respondents were residents of Virginia, others were from Maryland, Pennsylvania, Ohio and the District of Columbia. They had a wide range of outdoor experience, from novices participating in their first overnight trip, to visitors with 20 years of backpacking experience. Only one of these visitors had not obtained the required backcountry camping permit.

We asked participants what prompted them to select their campsite. Their preferences followed three broad themes: convenience, aesthetics and campsite qualities. Campsite qualities, such as flat ground, available 'bear hang trees', campsite size and a lack of rocks, composed the primary consideration for most respondents, at $47 \%$ of mentions. Aesthetic factors, including nearby waterfalls, 'fishing holes', cliff faces and 'quiet spots' were of secondary consideration at $29 \%$. Convenience considerations, such as the distance to the trailhead, the timing of the day and fatigue accounted for $24 \%$ of mentions.

We also asked them to articulate their understanding of SNP's camping policy. Ninety-seven per cent were able to describe some aspect of SNP's camping policy and 33\% specifically mentioned camping on pre-existing or established campsites (an open-ended question). More specifically, 19\% mentioned the distance of campsites to park trails and $18 \%$ mentioned low impact camping practices as primary concerns. Of secondary importance were distance to water source directives at $14 \%$ of mentions, with camping in established campsites and bear precautions close behind at 13\% each. The distance to other campers, park structures, park roads and boundaries, and fire prohibition each merited 5-7\% of mentions.

The interviewees who successfully articulated the established campsite policy were also asked to identify the factors that allowed them to select an established site. Bare ground was the most commonly cited identification method (34\% of mentions). Flat ground, fire rings and tent sites were also mentioned as secondary methods for campsite identification $(18 \%, 16 \%$ and $14 \%$, respectively). Access trails and trash were of lesser importance each gaining 9\% of mentions.

When asked to identify their source for information regarding the park's campsite policy, interviewees cited two primary sources: the camping brochure that accompanied permits achieved $41 \%$ of mentions and park rangers merited $33 \%$. Prior knowledge of the area and suggestions by others were also important sources, at a combined 14\% of response units, with the Internet, books and trailhead signs comprising 
the remaining responses at $6 \%, 4 \%$ and $2 \%$ of mentions, respectively.

\section{DISCUSSION}

The objective of a containment strategy for minimizing camping impacts is to concentrate overnight use onto a small number of sites, and, on each site, to minimize the extent of disturbance by spatially concentrating traffic (Leung \& Marion 1999; Marion \& Farrell, 2002). Because of the curvilinear nature of the use/impact relationship, campsites receiving more intensive visitation and traffic will suffer only marginal increases in size and loss of vegetation cover and organic litter (Cole 1982, 1992). By increasing visitation to selected campsites, other sites may be closed, resulting in a reduction in the areal extent of indicator measures at a travel zone or protected area scale. These anticipated findings were validated by results from this study. Substantial reductions occurred in the aggregate extent of the three primary campsite impact indicators, namely campsite area $(51 \%)$, area of vegetation loss $(44 \%)$ and area of exposed soil $(16 \%)$ (Table 2$)$. With the previous dispersal strategy there were 73 campsites with $2122 \mathrm{~m}^{2}$ of disturbed area. The established campsite policy reduced this to 37 campsites and a disturbed area of $1049 \mathrm{~m}^{2}$. This is primarily attributed to a $49 \%$ reduction in the number of campsites, most of which were effectively closed by rehabilitation work and natural causes.

Other factors may also have contributed to these reductions in areal measures of camping disturbance. Overnight backcountry use levels both Park-wide and within the three study areas declined during the study period (Table 1). Reductions in use could explain why visitors only used 24 of the 41 legal campsites heavily enough for them to remain open and established (Table 2). Natural disturbances such as wildfire and parasitic insects may have also contributed to reductions in camping impacts. A wildfire in autumn 2000 burned part of one study area, killing some trees and opening the overhead canopy. The subsequent deadfall and increased sunlight contributed to the closure and recovery of some campsites. Similarly, recent losses of eastern hemlocks from the Asian hemlock woolly adelgid may have caused similar effects. These natural events prompted the closure of several sites, as evidenced by the large number of recovered sites that received no active rehabilitation work.

Illegal sites declined in number (from 32 to 13), mean size (from $30 \mathrm{~m}^{2}$ to $20 \mathrm{~m}^{2}$ ) and aggregate area (from $961 \mathrm{~m}^{2}$ to $262 \mathrm{~m}^{2}$ ) (Table 2). These findings suggest that park efforts to educate visitors to select only the established sites, and site closure and rehabilitation work have been effective. Rehabilitation data indicates that visitors pushed aside the organic debris piled on closed campsites only nine times in 2000 and eight times in 2001.

As might be expected, given the curvilinear impact/use relationship, the campsites selected by managers to remain open did not deteriorate substantially, despite an estimated $53 \%$ increase in average visitation (from 19 to 29 nights $\mathrm{yr}^{-1}$ ). Mean campsite size, area of vegetation loss and area of exposed soil increased only marginally (Table 2). A comparison of conditions in 21 legal campsites assessed in 1999 and 2002 revealed small increases in campsite area $\left(33 \mathrm{~m}^{2}\right.$ to $\left.34 \mathrm{~m}^{2}\right)$ and larger increases in the area of vegetation loss $\left(8 \mathrm{~m}^{2}\right.$ to $\left.9 \mathrm{~m}^{2}\right)$ and area of exposed soil $\left(3 \mathrm{~m}^{2}\right.$ to $\left.5 \mathrm{~m}^{2}\right)$. These results follow Cole's (1992) theoretical campsite impact model. The surprisingly small increase in campsite area may be attributed to careful selection of campsites with low expansion potential (as a result of topographic limitations, rockiness or dense vegetation) under sustained high use. Although campsite size was not a selection criterion, the closure of large sites close to trails or water sources could also contribute to these findings. From a managerial perspective, the limited deterioration of legal established campsites is more than offset by aggregate impact reductions on closed campsites.

\section{Closure and rehabilitation success}

The rehabilitation efforts in the three study areas were integral to the success of the management policy because poorly located and fragile campsites were effectively closed to visitor use through the placement of organic debris. The effort devoted to the rehabilitation efforts was consistent annually, but was also realistic based on SNP's budget and staffing. We also note that the number of illegal sites dropped sharply (from 32 in 1999 to 13 in 2002) during the study, suggesting that following the initial transition period, ongoing rehabilitation work will become more manageable. Although this study did not include assessments of vegetative recovery on closed sites, undisturbed leaf litter and/or vegetative growth covered them and complete ecological recovery should occur if the closures remain successful.

These findings contrast sharply with those of Cole and Ranz (1983) and Hall (2001), in which campsite closure efforts were largely unsuccessful in western USA wilderness areas. They are more consistent with the campsite containment programme evaluated by Spildie et al. (2000), which reported a $37 \%$ reduction in aggregate disturbed area and $43 \%$ reduction in exposed soil. The success of site closures in this study can be attributed to the persistent rehabilitation efforts of park managers and the recovery of many sites through natural causes such as downed trees and fallen leaves. The resilience of the SNP environment, especially when compared to the western, high-altitude study areas of other studies, is also a contributing factor. Marion and Cole's (1996) research on eastern USA riparian campsites closed to use showed extremely high recovery rates, in part because of favourable growing conditions. SNP's soils and growing conditions are generally less favourable than those, but are probably more favourable to plant recovery than conditions in most western areas. 


\section{Education efforts}

Visitor interviews revealed that managers conveyed campsite selection messages successfully, but could improve efforts to communicate the established campsite aspect of the policy. Although many visitors successfully articulated park policies regarding campsite distances from trails, water, park buildings and other visitors, the distances cited were often vague, confused or inaccurate. Since the park brochures and permits list these distances, visitors are able refer to the provided literature to obtain accurate values when necessary. Since all of the legal sites left open by park managers met the distance requirements, visitors who chose an established site would inevitably meet the criteria regardless of their knowledge level. Nonetheless, SNP managers could improve the educational message by simplifying the educational content and focusing on the primary policy goals, such as selecting an established campsite.

\section{Balancing resource protection and visitor experience mandates}

A principal challenge in camping management decisionmaking is balancing the protection of natural resources with the provision of high quality camping experiences. In SNP's high use areas, problems with campsite proliferation and site expansion are addressed through the use of wellmarked designated campsites constructed using cut-andfill techniques in sloping terrain (Marion \& Farrell 2002). Limiting the number of sites in each area and providing adequate separation between campsites provides greater opportunities for visitor solitude. However, while this strategy effectively limits resource impacts, visitors lose campsite choices and must be prepared to hike further to find an open site.

The established campsite policy was developed as an effort to restrict camping to a limited number of resistant campsites while maintaining visitor flexibility and choice in campsite selection. Prior to the study, campsite occupancy rates in the study areas averaged $16 \%$. Based on the 1999 campsite occupancy survey, site numbers were reduced so that occupancy rates on average high use weekends (not peak use) would approximate $33 \%$. This would allow visitors to choose from an average of three campsites, while substantially reducing the aggregate extent of impact associated with an unregulated camping option. However, campsite occupancy rates for legal campsites in the study rose to $50 \%$ because visitors chose not to use 17 campsites, suggesting that managers could have selected additional sites for closure.

Decreasing the number of campsites and mean number of visible sites from 1 to 0.4 , while increasing the mean distance between adjacent campsites from $15 \mathrm{~m}$ to $18 \mathrm{~m}$, increased the potential for visitor solitude while camping. This success can be attributed to the reduction in campsite numbers and to selection criteria that included inter-campsite visibility and distances. The 17 additional established campsites that recovered because visitors did not use them were more remote from trails and other campsites and offered visitors greater solitude than those that many selected and used.

SNP's established campsite policy and the closure of unneeded campsites were accomplished through relatively non-restrictive regulations (to select an existing campsite), careful site selection, visitor education and site rehabilitation. Visitors were probably unaware of the management attention that had gone into the selection of resistant, well-spaced campsites or of the ongoing efforts to close poorly located or unnecessary campsites. Under the established campsite policy visitors retained a significant degree of choice in their campsite selection, including the ability to search out and discover 'natural' unmarked sites that suited their needs.

SNP managers could have designated a substantially smaller number of campsites and operated a reservation system to ration their use. While this option could have further minimized the area of camping disturbance, such enhanced protection would have 'cost' visitors their ability to have flexible itineraries and select campsites of their choosing. Alternatively, managers could have designated the campsites with signposts and symbols on maps without a reservation system. This option would probably have reduced the extent of site rehabilitation required but would have also reduced the naturalness of wilderness environments, and visitors' campsite choices and perceptions of exploring and finding a primitive unmarked campsite.

\section{CONCLUSIONS}

A visitor impact containment strategy and established campsite policy successfully reduced the number of campsites and aggregate measures of camping-related disturbance at $\mathrm{SNP}$, while minimizing restrictive regulations, site facilities and staff resources. SNP managers are planning to expand site containment and rehabilitation efforts to other Park areas. Park staff may modify the policy when full implementation occurs; temporary closure signs may be placed on campsites that experience repeated reuse. Alternatively, partially buried rocks in the best tenting spots may discourage campers.

We sought to integrate physical measurements evaluating the potential for camping solitude, with visitor interviews addressing important dimensions of the Park's success in implementing new camping policies. Such studies are rare, but may support more informed decision-making. Adaptive management collaboration between scientists and managers improved selection and implementation of effective camping policies. Objective documentation of such 'real world' management case studies can improve technology transfer.

One problem with adaptive management research is its potential to constrain experimental designs. In this study, we were unable to randomize the selection of study sites and reductions in overnight visitation were a confounding influence. Extended longitudinal studies of management success with alternate camping policies are needed to evaluate their efficacy. An improved understanding of rehabilitation 
options and recovery on closed campsites is needed to gauge long-term success and recovery rates. Visitor preferences for alternate camping policies and their perceptions of resource and social conditions on campsites under different policies also merit further study.

In summary, an established campsite policy contains camping impacts within selected resistant sites that enhance the potential for solitude, while providing the option to choose a primitive campsite. Application of the established campsite policy to other parks and protected areas would require similar camping regulations, educational messages, low to moderate use levels and the ability to sustain ongoing site rehabilitation work. An established campsite policy also requires a greater number of campsites and resource disturbance than a designated site policy, as resource protection has to be balanced against the provision of high quality recreation opportunities.

\section{ACKNOWLEDGEMENTS}

The USA National Park Service funded this research. We extend our thanks to the staff of Shenandoah National Park, especially Steve Bair and Mary Cottone. We also appreciate the thoughtful guidance and thorough reviews of Kevin Larkin and Joe Roggenbuck.

\section{References}

Bellamy, J.A., Walker, D.H., McDonald, G.T. \& Syme, G.J. (2001) A systems approach to the evaluation of natural resource management initiatives. Fournal of Environmental Management 63: 407-423.

Cole, D.N. (1982) Wilderness campsite impacts: effect of amount of use. General Technical Report INT-284, USDA Forest Service, Intermountain Research Station, Ogden, UT, USA.

Cole, D.N. (1989a) Wilderness campsite monitoring methods: a sourcebook. General Technical Report INT-259, USDA Forest Service, Intermountain Research Station, Ogden, UT, USA.

Cole, D.N. (1989b) Area of vegetation loss: a new index of campsite impact. Research Note INT-389, USDA Forest Service, Intermountain Research Station, Ogden, UT, USA.

Cole, D.N. (1992) Modeling wilderness campsites: factors that influence amount of impact. Environmental Management 16(2): 255-264

Cole, D.N. (1993) Campsites in three western wildernesses: proliferation and changes in condition over 12 to 16 years. Research Paper INT-463, USDA Forest Service, Intermountain Research Station, Ogden, UT, USA.

Cole, D.N. (1995) Disturbance of natural vegetation by camping: experimental applications of low-level stress. Environmental Management 19(3): 405-416.

Cole, D.N. \& Marion, J.L. (1988) Recreation impacts in some riparian forests of the eastern United States. Environmental Management 12(1): 99-107.

Cole, D.N. \& Ranz, B. (1983) Temporary campsite closures in the Selway-Bitterroot Wilderness. Fournal of Forestry 81(11): 729-732.

Cole, D.N., Peterson, M.E. \& Lucas, R.C. (1987) Managing wilderness recreation use: common problems and potential solutions. General Technical Report INT-230, USDA Forest Service, Intermountain Research Station, Ogden, UT, USA.

Cole, D.N., Watson, A.E., Hall, T.E. \& Spildie, D.R. (1997) Highuse destinations in wilderness: social and biophysical impacts, visitor responses and management options. Research Paper INTRP-496, USDA Forest Service, Intermountain Research Station, Ogden, UT, USA.

Farrell, T.A. \& Marion, J.L. (2000) Camping impact management at Isle Royale National Park: an evaluation of visitor activity containment policies from the perspective of social conditions. In: Wilderness Science in a Time of Change Conference, Volume 5: Wilderness Ecosystems, Threats, and Management, compiled D.N. Cole, S.F. McCool, W.T. Borrie \& J. O'Loughlin, pp. 110-114. USDA General Technical Report RMRS-P-15-VOL-5. Ogden, UT, USA: USDA Forest Service.

Hall, T.E. (2001) Changes in wilderness campsite conditions resulting from implementation of a designated-site camping policy. Management Report, USDA Forest Service, Aldo Leopold Wilderness Research Institute, Missoula, MT, USA.

Hammitt, W.E. \& Cole, D.N. (1998) Wildland Recreation: Ecology and Management. Second Edition. New York, NY, USA. John Wiley \& Sons Publishing.

Holling, C.S. (1978) Adaptive Environmental Assessment and Management. New York, NY, USA: John Wiley \& Sons Publishing.

Lessard, G. (1998) An adaptive approach to planning and decisionmaking. Landscape and Urban Planning 40: 81-87.

Leung, Y. \& Marion, J.L. (1999) Spatial strategies for managing visitor impacts in national parks. Fournal of Park and Recreation Administration 17(4): 20-38.

Leung, Y. \& Marion, J.L. (2000) Recreation impacts and management in wilderness: a state-of-knowledge review. In: Wilderness Science in a Time of Change Conference, Volume 5: Wilderness Ecosystems, Threats, and Management, compiled D.N. Cole, S.F. McCool, W.T. Borrie \& J. O'Loughlin, pp. 23-48. USDA General Technical Report RMRS-P-15-VOL-5. Ogden, UT, USA: USDA Forest Service.

Manning, P. \& Cullum-Swan, B. (1994) Narrative, content and semiotic analysis. In: Handbook of Qualitative Research, ed. N.K. Denzin \& Y.S. Lincoln, pp. 463-477. Thousand Oaks, CA, USA: Sage Publications.

Marion, J.L. (1991) Developing a natural resource inventory and monitoring program for visitor impacts on recreational sites: a procedural manual. Report NPS/NRVT/NRR-91/06, USDI National Park Service, USA.

Marion, J.L. (1995) Environmental auditing: capabilities and management utility of recreation impact monitoring program. Environmental Management 19(5): 763-771.

Marion, J.L. \& Cole, D.N. (1996) Spatial and temporal variation in soil and vegetation impacts on campsites. Ecological Applications 6(2): 520-530.

Marion, J.L. \& Farrell, T. (2002) Management practices that concentrate visitor activities: camping impact management at Isle Royale National Park, USA. Fournal of Environmental Management 66(2): 201-212.

Marion, J.L. \& Merriam, L.C. (1985) Recreational impacts on well-established campsites in the Boundary Waters Canoe Area Wilderness. Station Bulletin AD-SB-2502, University of Minnesota, Agricultural Experiment Station, St Paul, MN, USA.

Marion, J.L., Roggenbuck, J.W. \& Manning, R. (1993) Problems and practices in backcountry recreation management: a survey 
of National Park Service managers. Natural Resources Report NPS/NRVT/NRR-93/12, USDI National Park Service, USA.

NPS (2001) National Park Service management policies [www document]. Accessed 15 September 2002. Washington, DC: USDI National Park Service. URL: http://www.nps.gov/ refdesk $/ \mathrm{mp} /$

NPS (2002) Public use statistic office: park-by-park visitation and acreage totals [www document]. Accessed 22 August 2002. URL: http://www.aqd.nps.gov/stats

Neuendorf, K.A. (2002) The Content Analysis Guidebook. Thousand Oaks, CA, USA: Sage Publishing.

Newsome, D., Moore, S.A. \& Dowling, R.K. (2002) Natural Area Tourism: Ecology, Impacts and Management. Clevedon, UK: Channel View Publications.

SNP (1998) Shenandoah National Park backcountry and wilderness management plan. USDI National Park Service, Luray, VA, USA.
Spildie, D., Cole, D.N. \& Walker, S. (2000) Effectiveness of a confinement strategy in reducing pack stock impacts at campsites in the Selway-Bitterroot Wilderness, Idaho. In: Wilderness Science in a Time of Change Conference, Volume 5: Wilderness Ecosystems, Threats, and Management, compiled D.N. Cole, S.F. McCool, W.T. Borrie \& J. O'Loughlin, pp. 199-208. USDA General Technical Report RMRS-P-15-VOL-5. Ogden, UT, USA: USDA Forest Service.

Washburne, R.F. \& Cole, D.N. (1983) Problems and practices in wilderness management: a survey of managers. Research Paper INT-304, USDA Forest Service. Intermountain Research Station, Ogden, UT, USA.

Williams, P. \& Marion, J.L. (1995) Assessing campsite conditions for limits of acceptable change management in Shenandoah National Park. Technical Report NPS/MARSHEN/NRTR95/071, USDI National Park Service, Luray, VA, USA. 